\title{
Culumbia OAníuersity
}

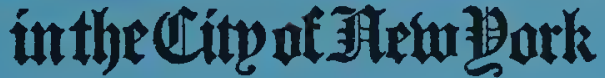

GEOPHYSICAL LABORATORY

DEPARTMENT OF GEOLOGY

\section{Technical Reports on Seismology}

No. 1

The "T" Phase of Shallow Focus Submarine Earthquakes 



\section{Columbia University \\ New York, N. Y.}

The "T" Phase of Shallow Focus Submarine Farthquakes

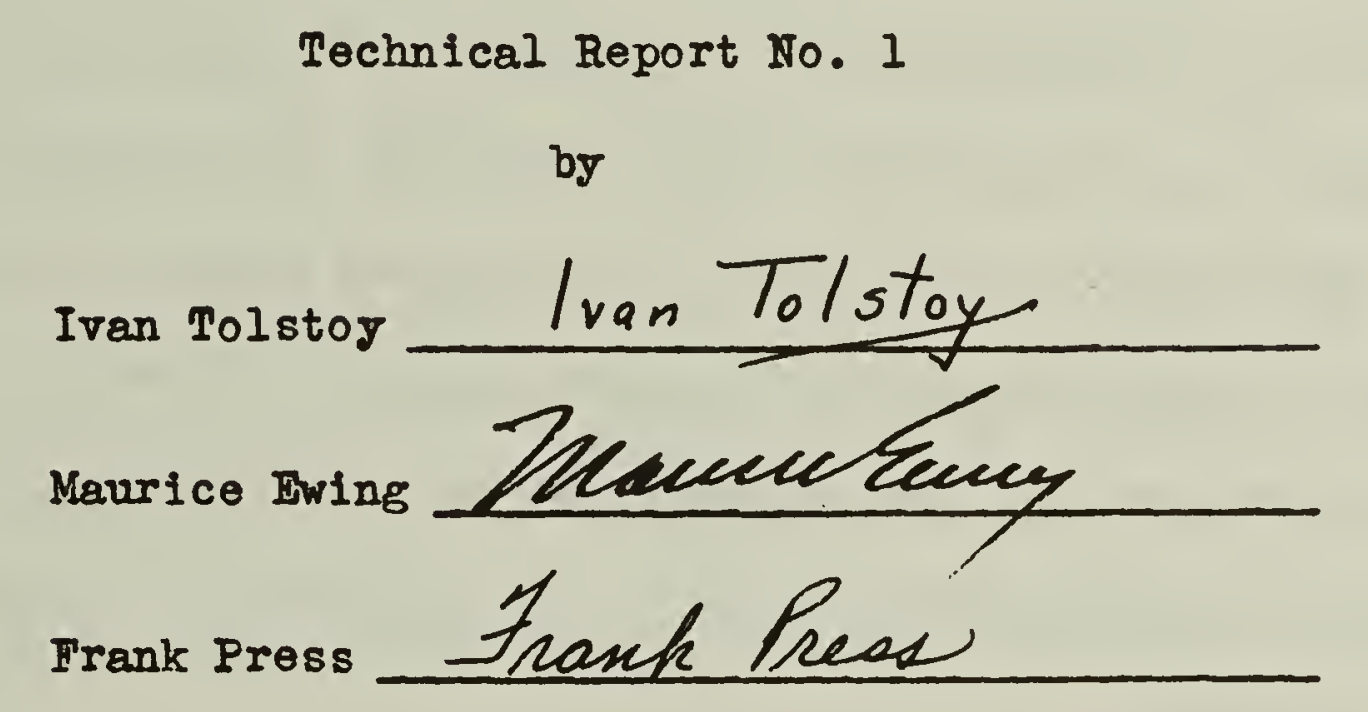

The research reported in this document has been made possible through support and sponsorship extended by the Geophysical Research Directorate of the Cambridge Fleld Station, AMC, D.S. Air Force, under Contract W-28-099 ac-396. It is published for technical information only and does not represent recommendations or conclusions of the sponsoring agency. 


\section{ABSTRACT}

A short period phase, 0.5 sec. perlod or less, travelling through the ocean with the velocity of sound in water has been identified on a large number of seismograms of earthquakes occurring at sea. This arrival was identified on the Benioff short period seismograms of the Weston, Fordham and Ottawa stations for a series of Dominican Republic Shocks, and on the Benioff short period seismograms of the Pasadena network of stations, the Mt. Hemilton and Mineral stations for a series of major Japanese and Aleutian shocks.

The existence of this phase had been noted previously by Iinehan who was at a loss to provide an explanation for them. The mechanism of propagation of the "T" phase is discussed and several practical applications are described. 


\section{INTRODOCTION}

In a recent paper, Press and Iw ing ${ }^{1}$ show that several types of oscillation can be transmitted over great distances in a system consisting of a liquid layer overlying an infinite elastic solid. The group velocity curves calculated for such a system indicate that a short period arrival (less than $0.5 \mathrm{sec}$. ), travelling with the speed of sound in water is theorectically possible. Actually this phase had been observed earlier by Worzel and twing ${ }^{2}$ in controlled experiments with explosive sound in shallow water. Eekeris ${ }^{3}$ adranced a theory of propagation of explosive sounds in two and three liquid layers which adequately explained the shallow water data.

In the work described above the velocity of sound in the liquid layer is constant with depth. In the deep ocean, howerer, the velocity of sound is known to have minimum value at a depth of approximately 700 fathoms. Fwing and Worzel ${ }^{4}$ have shown that sounds originating near the depth of minimum velocity (called the axis of the sound channel) would propagate over long distances with little attenuation. Signals from small bombs propagated in this

1. Frank Press and Maurice Bwing, A Theory of Microseisms with Geological Applications, Trans. Amer. Geoph. Union, Vol. 29, No. 2, pp 163-174, 1948

2. J. I. Worzel and Maurice Fwing, Explosive Sounds in Shallow Water, in Propagation of Sound in the Ocean, Mem. No. 27, Geol. Soc. Amer.. 1948

3. C. I. Pekeris, Theory of Propagation of Explosive Sounds in Shallow Water, in Propagation of Sound in tho Ocean, Mem. No. 27, Geol. Soc. Amer., 1948

4. Maurice Ewing and J. L. Worzel, Iong Range Sound Transmission, in Propagation of Sound in the Ocean, Mem. No. 27, Geol. Soc. Amer., 1948 
manner have been heard at distances up to 3100 miles.

It was therefore considered quite likely that a short period phase travelling with the speed of sound in water would be Identifiable on seismograms of earthquakes occurring at sea. Either of the above methods of propagation, or a combination of both, could account for the occurrence of this phase. We will now proceed to describe and discuss some of the results obtained.

\section{The "Tn Phase Observed at Weston}

The presence of this phase had already been noted by Inehan who named it the "T" phase. He was aware of the fact that apparently none of the classical earthquake phases provided an adequate explanation for them, and that they were not aftershocks. We have made a thorough study of arrival times of the "T" phase for 20 shocks on the Weston, Fordham and Ottawe recordings, and have come to the conclusion that this is precisely the short period phase predicted by the theory.

It fails to show up on instruments of longer period. The Fordham Galitzin, the Ottawa long period Benioff and MilneShaws, the Weston long period Benioff seismograms do not show it (the latter do show it for the large shocks, but with considerably smaller amplitudes than on the short period).

At Weston the "T" phase has an amazing amplitude, as may be seen from Table 1. This table gives:

(1) The date and origin time (H) of the shock

5. Daniel Iinehan, Earthquakes in the West Indian Region, Trans. Amer. Geophys. Union, pt.II, pp 229-232, 1940 
(2) The time of recording of initial motion ( $P P$ or $1 P$ )

(3) The P-S interval. This is given in order to provide a basis of comparison for the epicentral distances of the smaller shocks, for which epicentral determinations are not avaliable.

- (4) The maximum double trace amplitudes in cm. of the $P$ and S groups on all three components, as a basis for making rough comparisons between the magnitudes of the various shocks.

(5) The Pasadena magnitudes for the larger shocks.

(6) The arrival time of $T$ (iT)

(7) The maximum double trace amplitudes in $\mathrm{cm}$. of all three T components.

(8) The root mean square of these.

(9) The travel times of $T(t . t=1 T-H)$ in $\mathrm{min}$. and sec.

(10) The total duration of the T phase in min. and sec., from $1 T$ to the latest time at which it is still possible to plck out short period vibrations above the nolse level.

For reference we have numbered these shocks from 1 to 20 .

A glance at this table reveals what appear to be puzzling 1rregularities in the travel times. The first impression is that they do not appear to be functions of the P-S interval. As a matter of fact it was suggested by Iinehan ${ }^{6}$ that in might well vary Inversely with P-S as happens with certain types of core ware. A more detalled investigation reveals that this is not so.

6. Daniel Ifnehan, 10c. cit.

- Since preparing this report it has been learned that the Weston horizontal component Benloff instruments are operated at $\frac{1}{3}$ the sensitivity of the rerticals, and that all components are $25 \%$ 108: sensitive in March. 


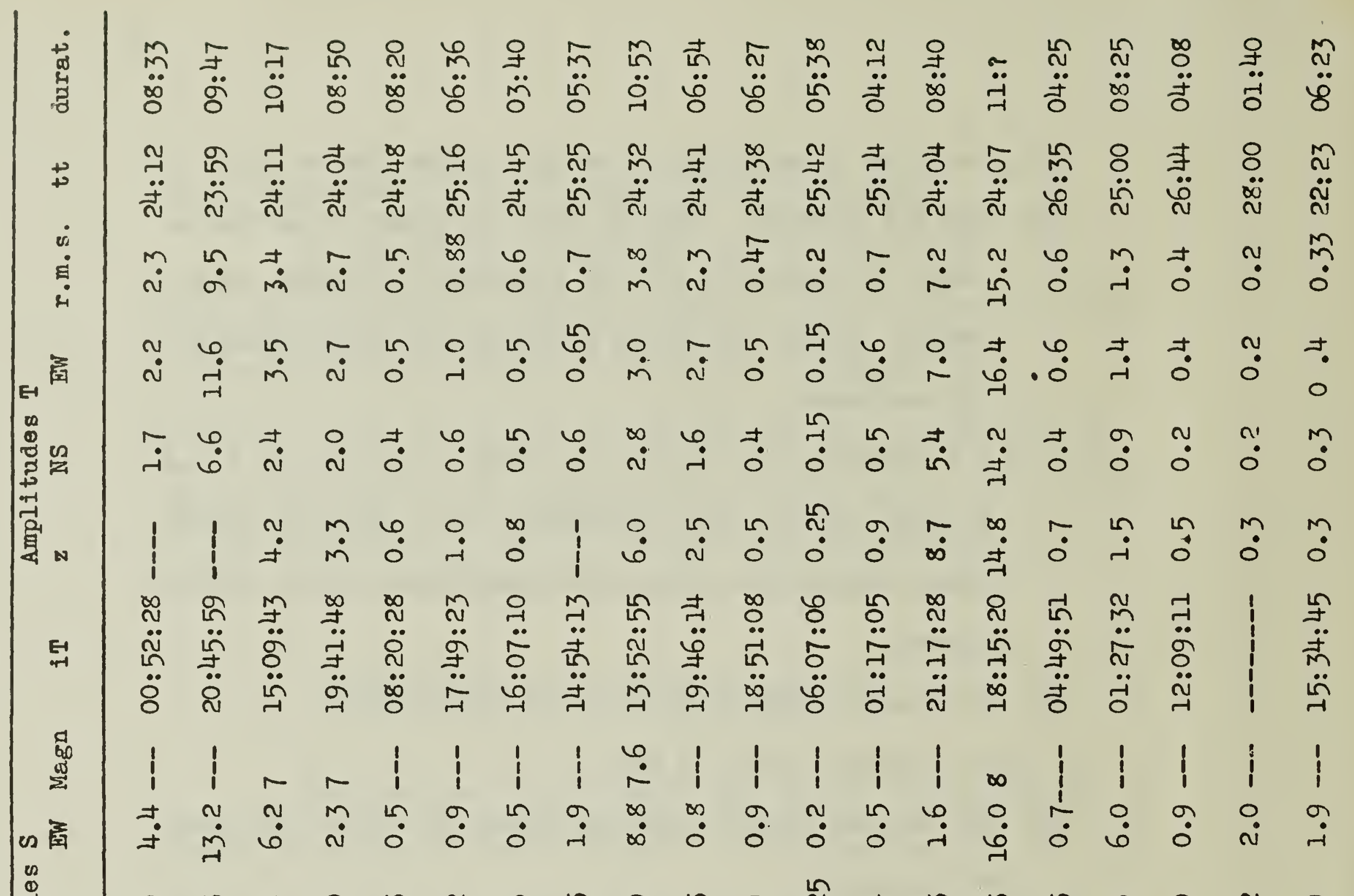

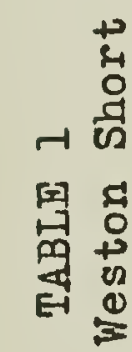

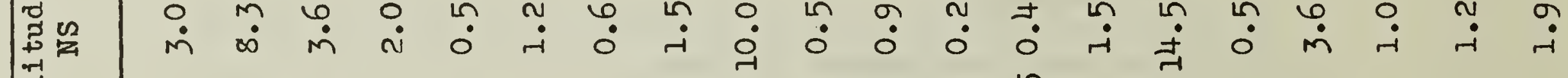

年

䋰

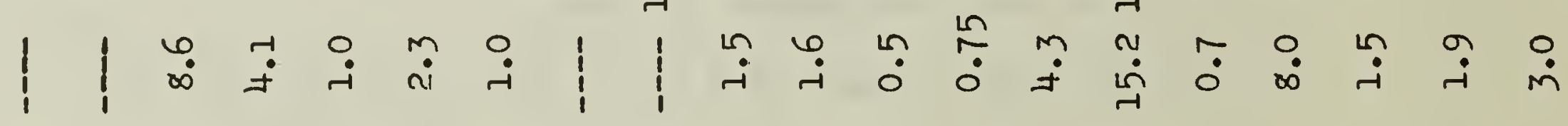

是

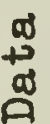

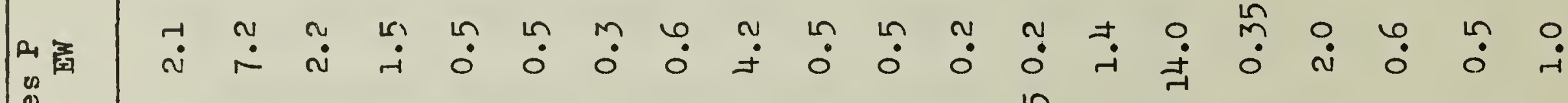

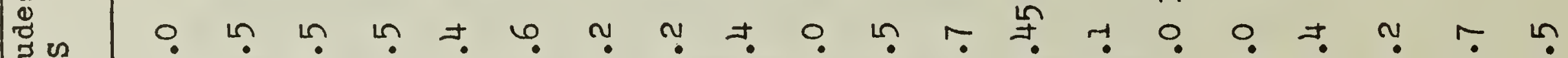

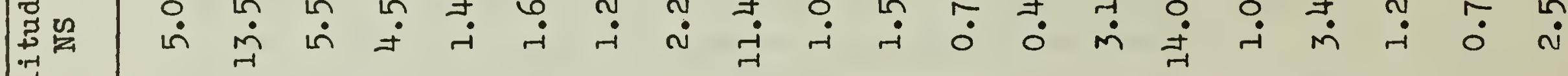

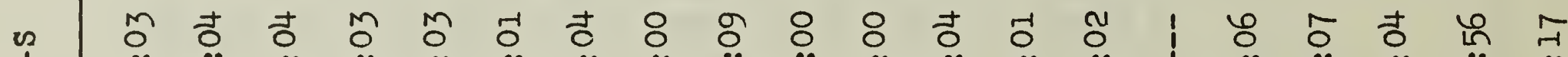

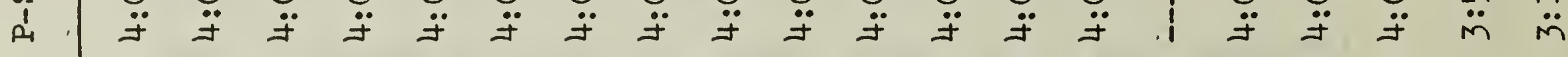

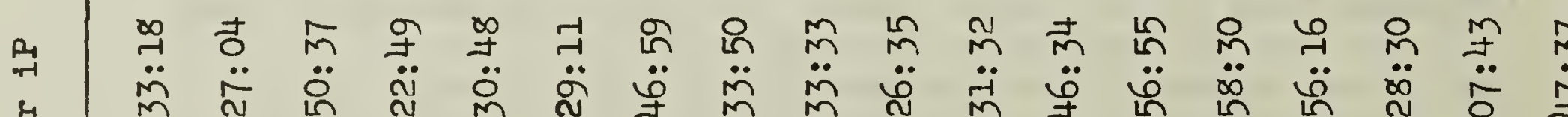

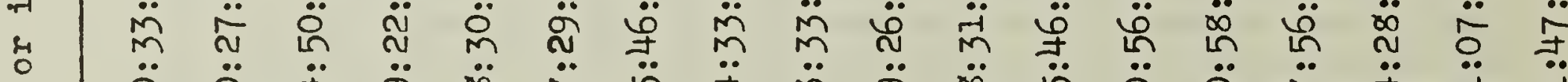

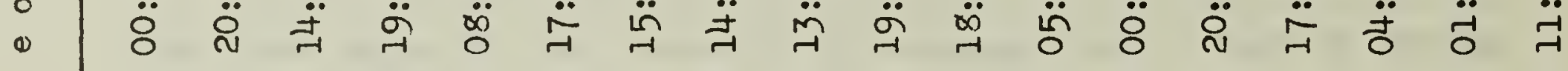

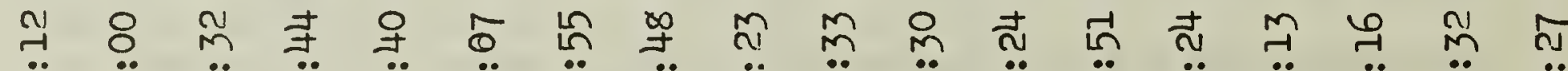

H.

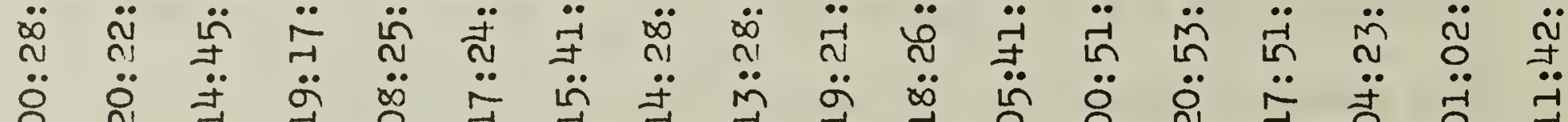

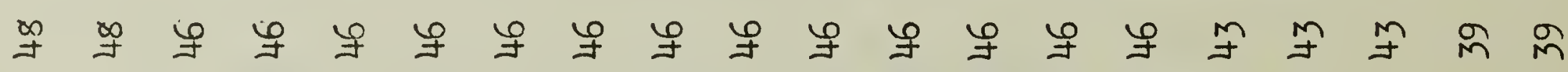

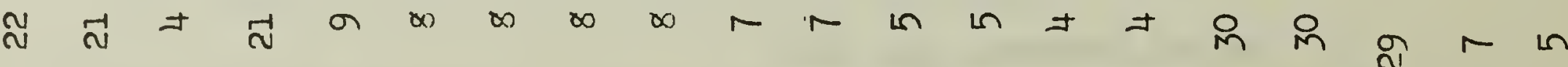

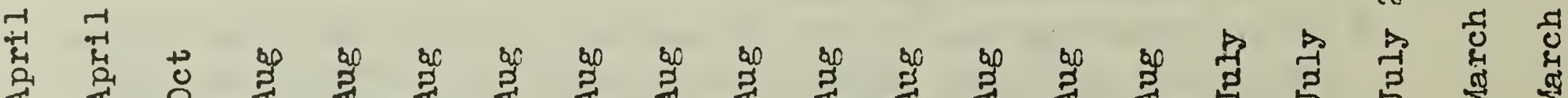

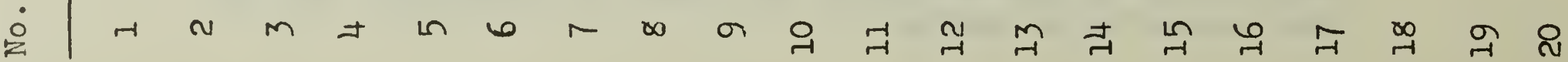




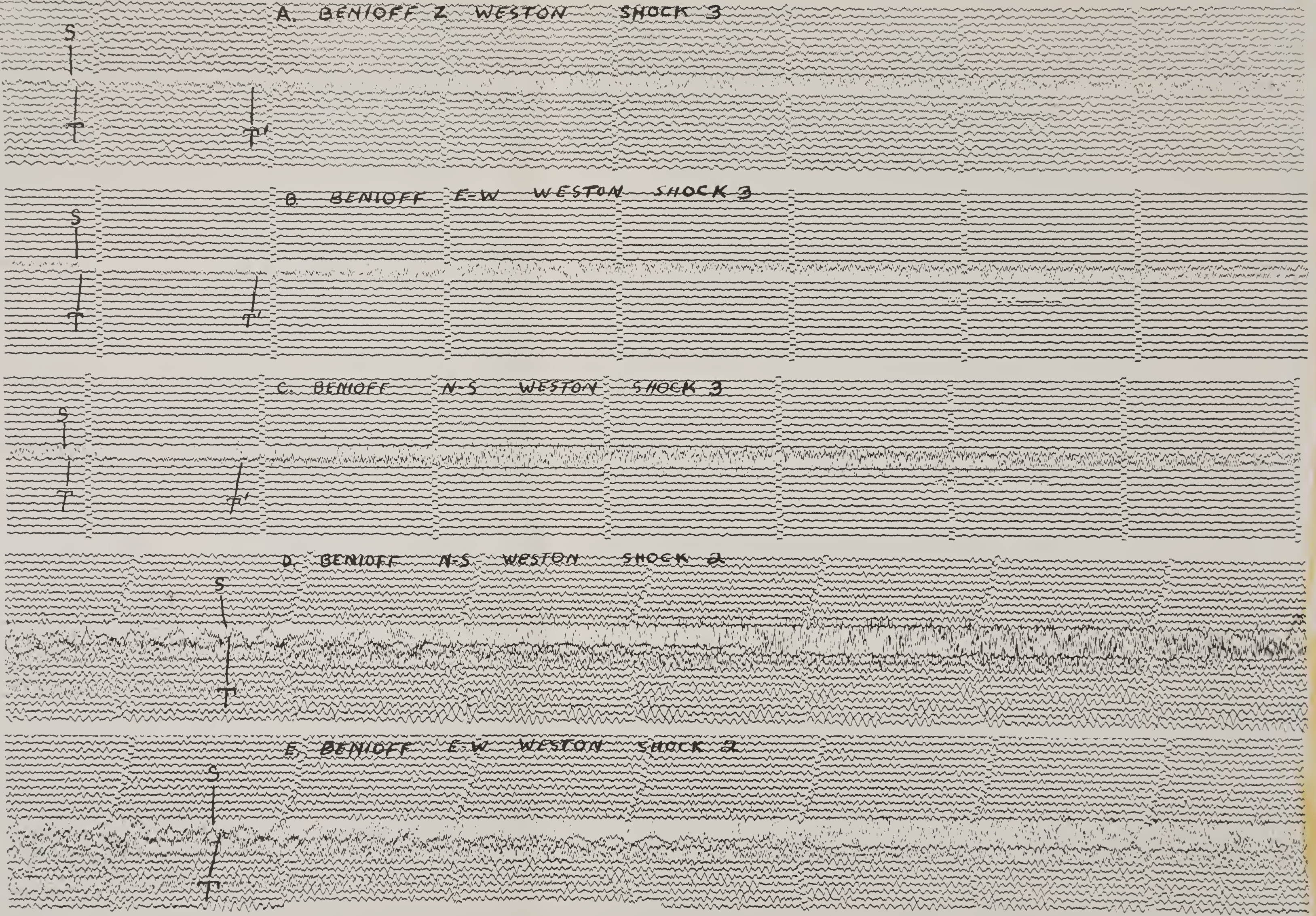

Fi gure I A, B, C, three components of the nT" phese recorded on the Heston short period Benloffs for the Dominican Republic shock of October 4,1946 ( $E=14: 45: 32$ ). D, $\mathbb{E}$,

horizontal components of the "Tn phase recorded on the Weston short period Bentoffs for the Dominican Republic shock of April 21, 1948 ( $E=20: 22: 00$ ). 


\section{Digitized by the Internet Archive in 2020 with funding from Columbia University Libraries}


Figure 1, A, B, C, shows the "Ti" phase as received by the three Benloff short period components at Weston for shock 3. It is seen that the "T" phase starts out very gradually. On many records T emerges very slowly out of the noise level, so slowly that for small amplitude "T" phases there is considerable doubt as to the true time 1T.

We have compared some of our times for iT with those given by Linehan in the NESA bulletins and have found that some of our estimates are considerably at variance with his. (from 10-15 sec. up to 1 min. differences). We have gone to great pains in order to pick the very first motion of $T$, at the precise instant at which it becomes distinguishable from the noise on the trace. In Figure $1, T$ is the time iT as picked by us and $T^{l}$ is the time picked by Iinehan.

We believe that the best illustration of what really happens is given by the curve in Figure 2. Here we have plotted the travel times of $T$ as recorded at Weston as a function of the r.m.s. of the maximum double trace amplitude of $T$. The curve shows that there is a well-defined law relating the amplitude of the T phase to the time 1T. For large amplitudes the travel times tend to an asymptotic value, which is of the order of $24 \mathrm{~min}$. for shocks having a P-S interval of $4 \mathrm{~min}$. $02 \mathrm{sec} . \pm 2 \mathrm{sec}$. For small amplitudes the travel time (or, more exactly, the apparent travel time) is much larger, lagging by as much as 2 to 4 min. behind the asymptotic value. This suggests that for small amplitudes, the beginning of the "T" phase is lost in the noise level. The largest apparent travel times is for shock 19, for which it is equal to 
28 min.

The maximum amplitudes of the "T" phase for all shocks reported in Table 1 occur in the interval 27 to $29 \mathrm{~min}$. after $\mathrm{B}$. We reproduce below the travel times of the maximu $T$ amplitudes for several shocks, including the minimum (shock 14) and maximom (shock 17) figures obtained.

Shock No. Travel Time of maximum T amplitude

$\begin{array}{lll}3 & 27 \text { min } & 58 \text { sec } \\ 4 & 27 & 20 \\ 5 & 27 & 33 \\ 6 & 27 & 29 \\ 7 & 27 & 13 \\ 14 & 27 & 03 \\ 17 & 28 & 59\end{array}$

The duration or spread of the "T" phase for each of these shocks throws further light on its behavior as a function of amplitude. The figures given for the duration in Table 1 are plotted as a function of r.m.s. double trace amplitude in Figure 3 . It is seen that the spread shows a very definite decrease for smaller amplitudes, and that the largest amplitudes correspond to the longest durations. Though the points of this graph do not group themselves quite as nicely as those of the curve in Figure 2, it appears none the less that for large amplitudes the duration reaches a limiting value, between 9 and 11 min., which corresponds to the minimum apparent travel time. It w1ll be shown that the minimum apparent travel time corresponds to the true travel time. The shortest duration is that of shock 19, for which it is $01 \mathrm{~min} .40 \mathrm{sec}$. We recall that this is also the shock that had the maximum apparent travel time. 


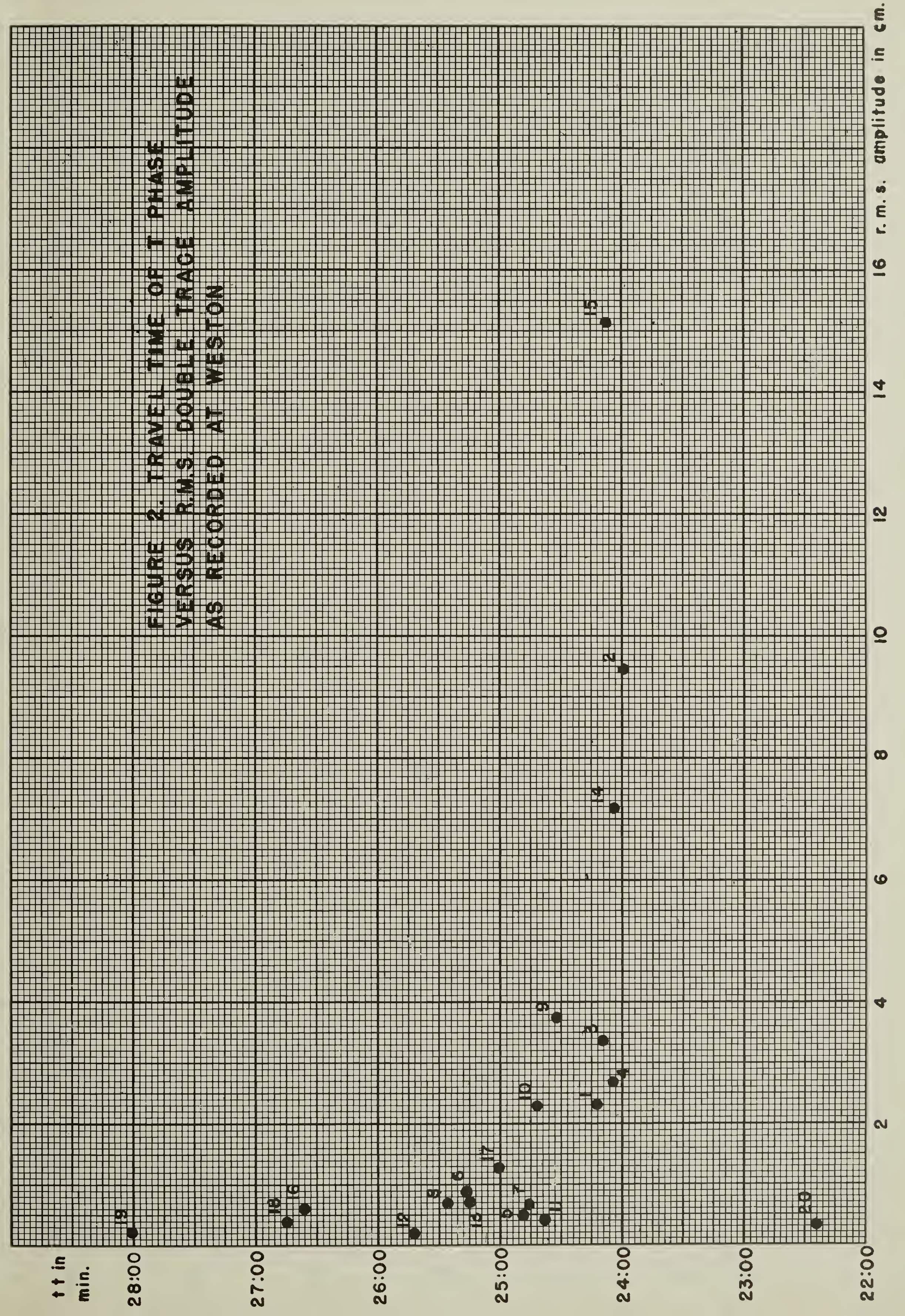




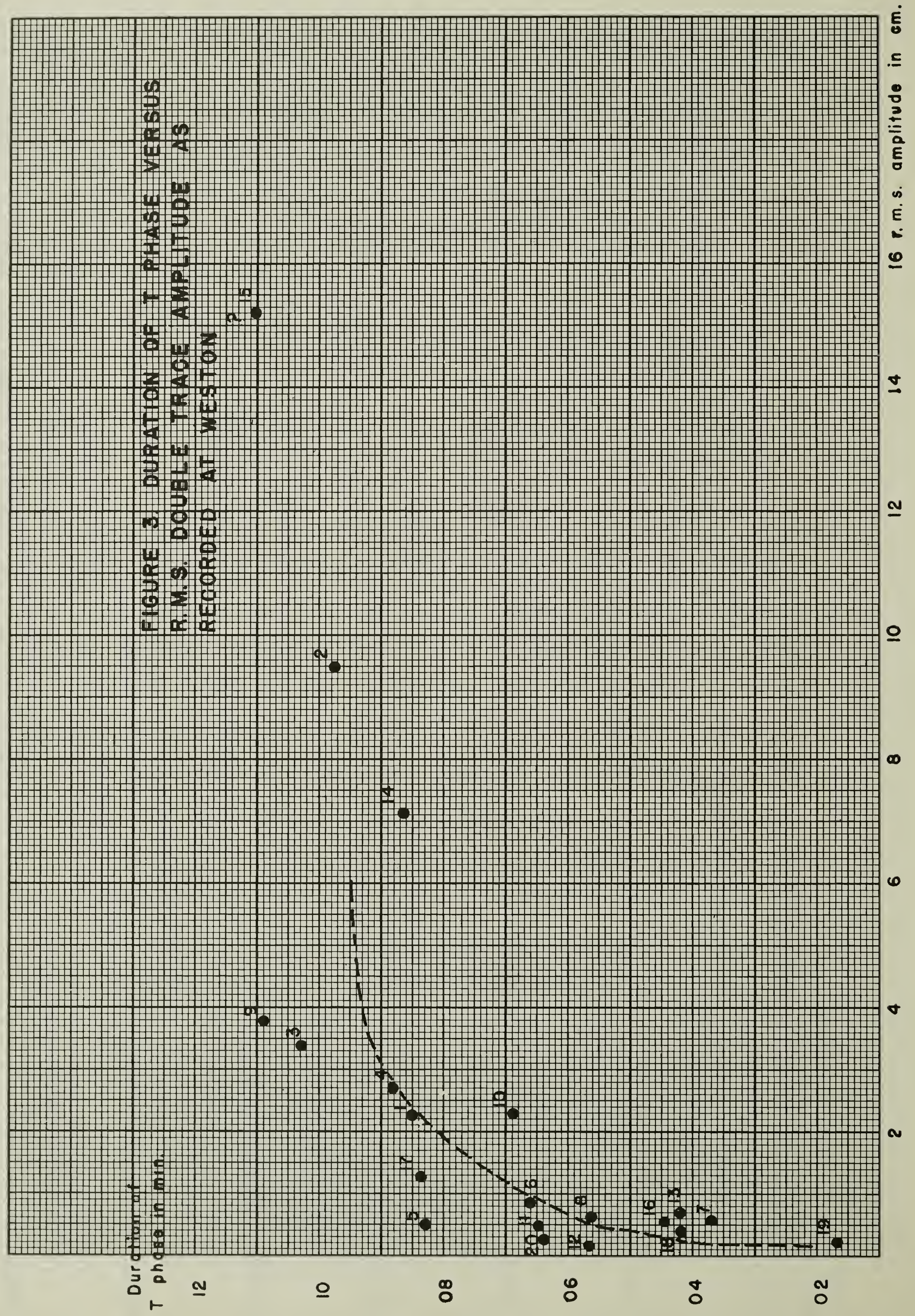


The curves in Figures 2 and 3 have therefore helped provide us with the following picture of the "T" phase of a series of Dominican Republic shocks recorded at Weston: for large shocks the "TH phase starts coming in about 24 min, after $H$, and lasts for as much as 9 to 11 min. until it once more merges into the background of short period noise. As the amount of energy it carries decreases, it emerges later and later from the noise background of the trace, and merges back into the noise level more and more rapidly. In other words, the smaller the amplitudes of the "T" phase, the later it seems to arrive and the shorter is its apparent duration on the record, until, for very small amplitudes only a very small and short signal is visible. As the amplitudes tend to zero the last portion of the signal to disappear is that which normally corresponds to the approximate center, where the largest amplitudes occur. This is what happens in particular for shock 19. Very small shocks, for which the maximum $P$ and $S$ amplitudes are of the order of $0.5 \mathrm{~cm}$. and less may show no "T" phase at all. One more feature, concerning the very large shocks, should be noted: the "T" phase of shocks 15, 9 and 2 is preceeded by a series of numerous, almost uninterrupted short period groups. IT was then picked at the beginning of the one long continuous group that was characterized by a steady rise to much larger amplitudes. (Figure ld and e). 


\section{The MTH Phase at Fordham and Ottawa}

These two stations are equipped with short period Benioff seismographs (vertical component only). For some of the preceeding shocks it was possible to obtain arrival times for the "T" phase at these stations. Both stations operate their Benioffs with a lower magnification, being troubled by a higher noise level, than the Weston station. From what we have just noted for the Weston "T" phases, we mast expect therefore that the apparent arrival times at Fordham and Ottawa will be somewhat later than the true times of 1T.

Table 2 gives the number of the shock, the origin time $\mathrm{H}$, the times 1T, the travel times tt, and the epicentral distance $\Delta$ for the Weston, Fordham and Ottawa stations. Many of the shocks studied at Weston did not produce any visible "T" phase on the records of the two latter stations because of the higher noise level and smaller magnification, and also, in the case of Ottawa, because of the decay of the "T" phase with distance. There is definite evidence showing that the "T" phase decays faster than the other phases of these shocks.

\section{Decay of the "T" Phase Amplitude with Distance}

Before drawing any conclusions from the arrival times figuring in Table 2, let us say a word about the decrease in amplitude of the "TH" phase with distance. Since the magnifications at Ottawa and Weston are different, and not too accurately known, and 


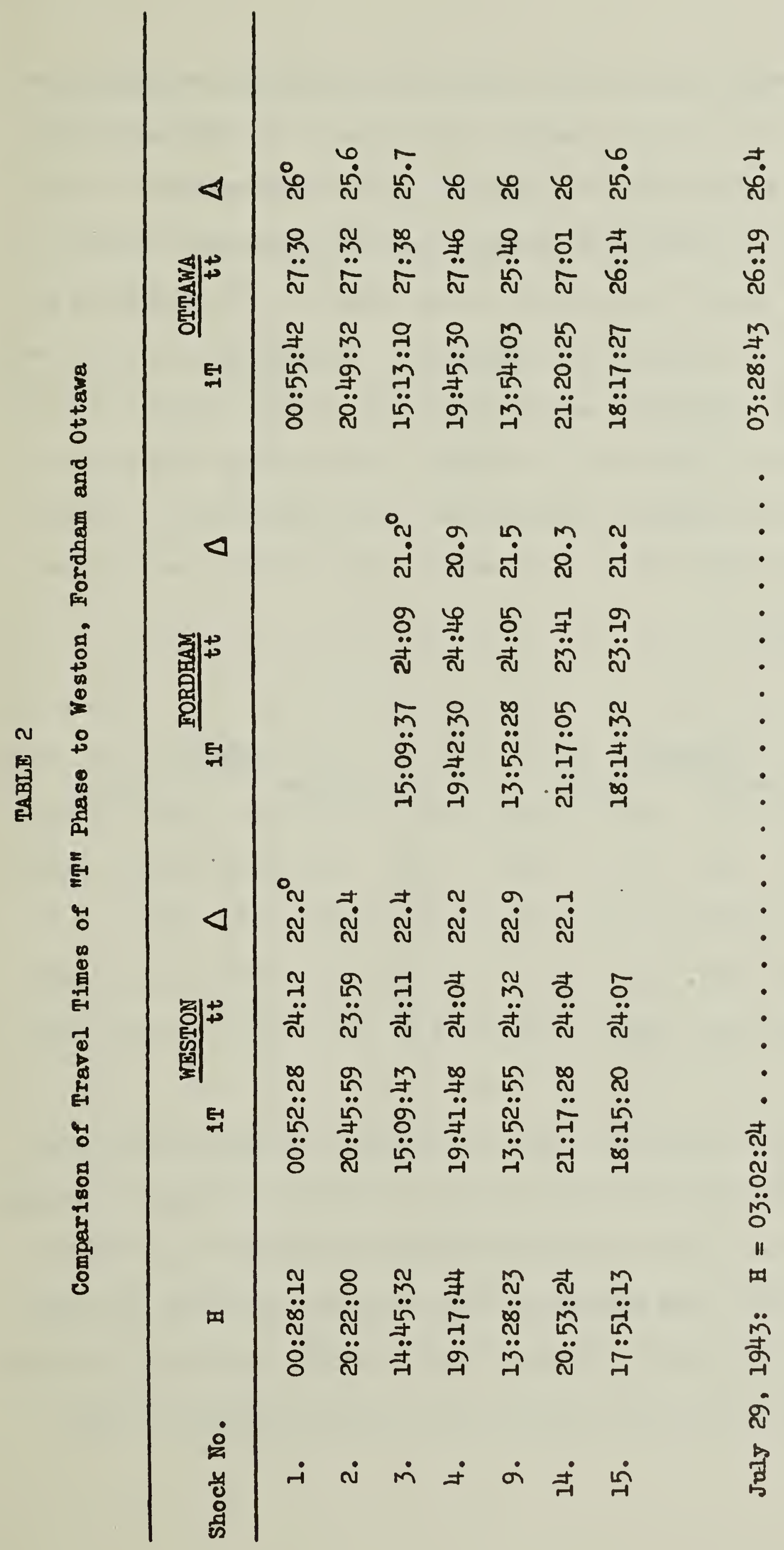


may have varied in time (the sensitivity is changed seasonably at Weston), it is not the absolute amplitudes of the "T" phase that will give us any rellable indications as to the behaviour of the "T" phose with increasing distance from the epicenter. It is better to obtain the variation of the ratios of the amplitudes of T to those of $P$ and $S$ in a given shock. A rough criterion will be provided by taking the maximum amplitudes of the "I" phase for any given shock at Weston and at Ottawa. The following figures give the vertical component maximum double trace amplitudes in $\mathrm{cm}$. at Weston and Ottawa for $P, S, T$ and the ratios of these amplitudes $T / P$ and $T / S$.

\begin{tabular}{|c|c|c|c|c|c|c|c|c|c|c|}
\hline \multirow{3}{*}{ Shock No. } & \multicolumn{5}{|c|}{ WESTON } & \multicolumn{5}{|c|}{ OTTAWA } \\
\hline & \multirow{2}{*}{\multicolumn{3}{|c|}{$\begin{array}{c}\text { Amplituaes } \\
\mathrm{C}\end{array}$}} & \multicolumn{2}{|c|}{ Ratios } & \multicolumn{3}{|c|}{ Amplitudes } & \multicolumn{2}{|c|}{ Ratios } \\
\hline & & & & $T / P$ & $\mathrm{~T} / \mathrm{S}$ & $P$ & $\mathbf{S}$ & $T$ & $T / P$ & $T / S$ \\
\hline 3. & 9.6 & 8.6 & 4.2 & 0.44 & 0.49 & 1.0 & 1.1 & 0.25 & 0.25 & 0.23 \\
\hline 4. & 7.4 & 4.1 & 3.3 & 0.44 & 0.8 & 0.7 & 0.5 & 0.2 & 0.29 & 0.4 \\
\hline 14. & 4.0 & 4.3 & 8.7 & 2.2 & 2.0 & 0.6 & 0.5 & 0.45 & 0.75 & 0.9 \\
\hline 15. & 15.6 & 15.2 & 14.8 & 0.95 & 0.97 & 6.0 & 5.9 & 2.0 & 0.33 & 0.34 \\
\hline
\end{tabular}

It is apparent therefore that the "T" phase decays mach more rapidly than the other phases of the Dominican Republic shocks, its amplitudes decreasing between Ottawa and Weston two to three times as fast. The duration of the "T" phase at Ottawa also gives evidence of 1 ts decay, though it does not give a reliable criterion, since its decrease will be due to the combined effects of decay 
with distance and of higher noise level together with lower sensitivity.

The durations of the "T" phase in min. and sec. at Ottawa and Weston for four large shocks compare as follows:

\begin{tabular}{ccc} 
Shock No. & Ottawa & Weston \\
\hline 3 & $5: 38$ & $10: 17$ \\
4 & $9: 09$ & $10: 53$ \\
14 & $6: 55$ & $8: 40$ \\
15 & $10: ?$ & $11: ?$
\end{tabular}

It is seen that the greatest decrease is for shock 3, which had at Weston the smallest "T" phase amplitude of all four shocks. It also had the latest arrival time at Ottawa, whereas shocks 9 and 15, the relative decrease in duration of which is smallest, have earlier arrival times.

This shows therefore that at Ottawa the arrival times behave in an exactly similar fashion to what was noted for Weston: the arrival times read off the records for small shocks are not the true arrival times, but apparent times, which give a total travel time which may be greatly in excess of the true figure. Due to the combined effects of decay with distance of the "T" phase and higher background at Ottawa, this source of error will affect shocks such as 3 and 4, which were barely large enough to give correct travel times at Weston. At Ottawa the duration of $T$ for shock 3 is 5 min. 38 sec. Unfortunately the tail of the "TN 
phase for shock 4 is obscured on the Ottawa record by an extraneous disturbance, but it may be seen to have a duration of probably less than 6 min. (end of disturbance), and more than 4 min. Its duration is therefore of the same order as that of 3 . If we now refer to Flgures 2 and 3 we see that at Weston, for a duration of $5: 30$, it obtained from the record should be corrected by an amount of the order of $1 \mathrm{~min}$. to $1 \mathrm{~min}$. $30 \mathrm{sec}$. As a rough approximation we may assume that the correction will be at least of the same order at Ottawa. The apparent travel times for 3 and 4 at ottawa being respectively $27: 38$ and $27: 46$, the true travel times would therefore be more like $26: 08$ to $26: 38$, and $26: 16$ to $26: 46$. These times are mach closer to those of the two larger shocks 9 and 15 as given in Table 2. In the present state of our knowledge, however, it is obviously impossible to obtain accurate travel times by making corrections of this kind. Nevertheless, the preceeding has served to emphasize the dependence on amplitude of the travel times obtained at ottawa for 1T. It is our opinion that the most reliable travel times are given by shocks 9 and 15. Times given by all the others may be in error by as much as 1 to $2 \mathrm{~min}$.

Examination of the Fordham records reveals a similar situation, namely, marked increase in apparent travel times with decrease in amplitude of T. The much higher background than at Weston must interfere seriously with the times of iT. There is another feature, for which we will provide a tentative explanation later, which is of interest: in spite of the lesser distance from the epicenter, the amplitudes of the "T" phase relative to $P$ and $S$ 
are smaller than at Weston. We reproduce below the figures for the amplitudes of P. S. T ( $z$ component) and for the ratios T/P, T/S at Fordham for shocks 3, 4, 14, 15. The last column gives again the figures for these two ratios as observed at Weston.

\begin{tabular}{|c|c|c|c|c|c|c|c|}
\hline \multirow{3}{*}{ Shock No. } & \multicolumn{5}{|c|}{ FORDHAM } & \multirow{2}{*}{\multicolumn{2}{|c|}{$\frac{\text { WESTON }}{\text { Ratios }}$}} \\
\hline & \multicolumn{3}{|c|}{ Amplitudes cm. } & \multicolumn{2}{|c|}{ Ratios } & & \\
\hline & $P$ & $S$ & $T$ & $T / P$ & $\mathrm{~T} / \mathrm{S}$ & $T / P$ & $T / S$ \\
\hline 3 & 0.9 & 1.5 & 0.3 & 0.33 & 0.2 & 0.44 & 0.49 \\
\hline 4 & 1.0 & 0.5 & 0.2 & 0.2 & 0.4 & 0.44 & 0.8 \\
\hline 14 & 0.7 & 1.0 & 0.5 & 0.7 & 0.5 & 2.2 & 2.0 \\
\hline 15 & 5.7 & 6.1 & 3.0 & 0.5 & 0.5 & 0.95 & 0.97 \\
\hline
\end{tabular}

Therefore for the same reasons as for the Ottawa records we will only consider as reliable the times given by the larger shocks, such as 9, 14, and 15. The durations of T of shocks 3,4, 9, 14, 15 at Fordham are respectively: $6: 29,4: 25,6: 20,7: 15,10: 20$.

It is interesting to note that the first "T "phase observed by the authors was recorded on a Macelwane-Springnether microbarograph which responded as a short period seismograph to the ground motion at Woods Hole, Massachusetts, caused by the Dominican Republic shock of August 4, 1946. As a result of the study of this record, the authors formalated their basic ideas on the nature of the "T" phase.

\section{The "T" Phase as a Short Period Water Wave}

We will now introduce the hypothesis that the "T" phase corresponds to a short period compressional wave travelling through 
the water as far as the continental shelf, and transmitted from there on as short period elastic waves travelling through the sediments and basement of the continent.

It is to be noted that the travel times increase with distance from the epicenter. The reverse relation, which could have identified the "T" phase as some new kind of core wave does not hold. A second important feature is obtained by calculating the velocity of the "T" phase at Fordham, Weston and Ottawa under the assumption of a homogeneous path. Dividing the distance by the travel time, we obtain for shocks 9 and 15 the following velocities:

\begin{tabular}{clll}
\hline Shock No. & Fordham & Weston & Ottawa \\
\hline 9 & $5430 \mathrm{ft} / \mathrm{sec}$ & $5680 \mathrm{ft} / \mathrm{sec}$ & $6150 \mathrm{ft} / \mathrm{sec}$ \\
15 & 5350 & 5660 & 5930 \\
\hline
\end{tabular}

The same pattern appears for the other shocks listed. Therefore, the average velocity increases with distance from the epicenter. This is the reverse of what would be observed for elastic waves reflected at the boundary of the core. Besides the travel times are much too large for either $P_{c} P$ or $S_{c} S$.

Weston is situated roughly north of the outer edge of the continental shelf. This means that for shock 9 (see Table 3), under the above hypothesis, $19.9^{\circ}$ of the total path would be 
through water as a compressional wave, $3^{\circ}$ as an elastic wave through the shelf. Three degress would be the distance to the 1000 fathom contour line. If therefore we subtract a rough value of the time which a $P$ wave takes to travel $3^{\circ}$ from the total travel time of $T$, we will get the velocity with which this latter phase has to travel through the water in order to arrive at the observed time. We may take for example 00:57 as the travel time of $P$ for $3^{0}$ (Dahm). The velocities obtained are given in Table 3 , Column 2. If we take $4^{\circ}$ as the maximum posstble distance from Weston at whic $\mathrm{h}$ the transformation from water wave to elastic waves begins to occur, we get the velocities shown in column 3 of Table 3. Four degrees Is a little more than the distance of the 2000 fathom contour south of Weston.

TABLE 3

Water Velocity of "T" Phase Recorded at Weston

Shock No.

$3^{\circ}$ Land Path

$4^{\circ}$ Land Path

1

2

3

4

9

14

15
$5020 \mathrm{ft} / \mathrm{sec}$

5120

5070

5050

5120

5020

5075
$4830 \mathrm{ft} / \mathrm{sec}$

4930

4880

4860

4940

4830

4900 
We see that these figures are respectively a little larger and a Ittle less than the true velocity of sound in sea water. These results can be considered extremely satisfactory. Thegindicate the water vaves first start entering the shelf on its slope, probably between the 2000 and 1000 fathom contours.

Similar calculations for Fordham yield comparable results. The transformation of the water wave into an elastic wave would first occur on the slope of the shelf, somewhere between the 2000 and 1000 fathom isobaths. Table 4 gives the velocities of the "T" phase through the ocean, assuming land paths of $2^{\circ}$ and $4^{\circ}$ through the continental shelf to Fordham.

TABLE 4

Water Velocity of "T" Phase Recorded at Fordham

\begin{tabular}{ccc}
\hline Shock No. & $2^{\circ}$ Land Path & $4^{\circ}$ Land Path \\
\hline 3 & $4970 \mathrm{ft} / \mathrm{sec}$ & $4560 \mathrm{ft} / \mathrm{sec}$ \\
9 & 5060 & 4670 \\
14 & 4830 & 4400 \\
\hline
\end{tabular}

These results are therefore essentially similar, though the velocities obtained are somowhat more irregular than at Weston. One of the obvious reasons for this is the much higher background at Fordham. 
The present theory therefore is in accord with the observed travel times of the "T" phase which we have noted. Thus it explains the more rapid decay of the "T" phase between Weston and Ottawa as compared with the other phases of the Dominican Republic shocks, since according to our hypothesis (seo section on mechanism of transmission), the energy it carries would decay more or less as the inverse first power of the distance through the water, and the inverse square of the distance from some point on the slope of the continental shelf, whereas the energy carried by the other phases would decay as the inverse square of the epicentral distance. It also explains the relatively lower amplitudes at Fordham. A glance at a bathymetric chart of the coast line of the eastern United States, shows that sound rays travelling from the Dominican Republic along a great circle path to Fordham would come in at an acute angle to the coast line and the edge of the shelf. Since the velocities of elastic waves and sound waves in the water are so different, there would occur under these conditions considerable reflection and refraction. Weston, on the contrary, Is situated north of a stretch of shelf that runs practically $\mathrm{E}-W$ for more than a hundred miles. The sound rays travelling along a great circle path from the Dominican Republic would here hit the shelf at practically normal incidence, or at least the angle of incidence would be quite small. On entering the shelf, there would be very little refraction, little reflection, and the corresponding decrease in peak intensity of the wave front would be relatively small. 
The theory also accounts for what we had called the increase of average velocity of the "T" phase between Weston and Ottawa. Qualitatively this is obvious. Let us see what the velocities between Ottawa and Weston are for the "T" phase. Since the all water portions of the path of the "T" phase at Weston, Ottawa and Fordham are approximately the same, we can draw travel time curves for these three stations simultaneously as a function of the epicentral distance only. In Figure 4 we have plotted the travel times for a few of the more reliable shocks (in the sense that they give a sufficiently good approximation for iT, as judged by the criteria explained above). The points obtained are rather scattered, and the various lines that could be drawn would give a wide variety of velocities. However, we note that the three times at Weston, Fordham and Ottawa for shock 9 fall on line 1. The point corresponding to the travel time of $T$ for 14 at Fordham also falls on this line which gives a velocity of about $3^{\circ}$ a minute which is approximately the correct velocity for $P$. However, it is obviously possible to interpret the points in Figure 4 as giving a line such as the line (2), which corresponds more to the velocity of S. Therefore, between Weston and Ottawa, the "T" phase is propagated with the velocity of bodily elastic waves. Whether this velocity is closer to that of $P$ or $S$, it is impossible to say. This shows that, since the average over-all velocity for the "TH" phase is found to be at Ottawa of the order of 6000 feet per sec, and since the velocity for the section of path between Weston 
and Ottawa is of the order of 12000 to 18000 feet per sec., at some point of the path, south of Weston there must occur a sharp decrease in velocity. From the nature of the computations made perviously, it is obvious that if we assume that the point at which this velocity changes is on the slope of the continental shelf, near the 2000 fathom isobath, the average velocity for the rest of the path (between this point and the Dominican Republic) has to be that of sound in water, providing we take the continental velocity as 18000 feet per sec.

There is one more piece of evidence in support of the theory. If the "T" phase is indeed propagated mostly through the water, very large differences in travel times would result from small differences of epicenter location relative to a given station. Roughly, for any two given shocks occurring in the same azimuth, the difference in travel time of the "T" phase would be five times the difference of their P-S intervals, and in the same sense. Thus in Figure 2, there are several points that demand attention because of their anomalous positions. Let us take $\mathrm{P}-\mathrm{S}=4 \mathrm{~min}$. $04 \mathrm{sec}$. as a standard and reduce all the points of the graph for this value assuming the land and sea velocities of the preceding paragraph. The result is shown in Figure 5. There has been a remarkable decrease in the scatter of the points of Figure 2, which fully confirms our hypothesis. In particular point 20 (shock $20, \mathrm{P}-\mathrm{S}=3: 17$ ) has been brought right up into the midst of the other points. Point 9 (shock 9 P-S $=4: 09$ ) has been brought down to fall right on the curve. The discrepancies can be explained by the inherent weaknesses 
of the P-S interval as a criterion for measuring distances combined with large variations of it observed for small variations in the epicentral distance, and also by personal errors and interference by noise.

It should be added that the "TI" phase for these shocks was also recorded on the Wood-Anderson seismometers at Seven Falls (E-W) and Schawinigan Falls $(\mathbb{N}-S)$, Canada. The magnification being of the order of 1400, the amplitudes of T are very small; the maximum double trace amplitude observed was $0.5 \mathrm{~mm}$. at Seven Falls, for the August 4, 1946, shock, and 0.25mm. at Schawinigan Falls for the same shock. The times that may be picked are erratic. The amplitudes at these two stations indicate that the ground motion has a large transverse component.

\section{Ground Motion of the NmN Phase at Weston}

It has already been pointed out by Iinehan ${ }^{7}$ that the $\mathrm{MN}$ phase has a large transverse component. A glance at the list of maximum double trace amplitudes* for the three components at Weston given in Table 1 shows this to be so; the maximum amplitudes occur for either the $\mathrm{z}$ or the EW component, and on the whole they are of the same order of magnitude. The NS component is usually the smallest.

We have made a detailed examination of the amplitudes of the various groups which can be distinguished in a few typical "T" phases, such as those of shocks $3,4,14$ and 17 . The results snow that, though the qualitative statement that the motion is predominantly

7. Daniel Iinehan, loc. cit.

* See footnote on page 5. 


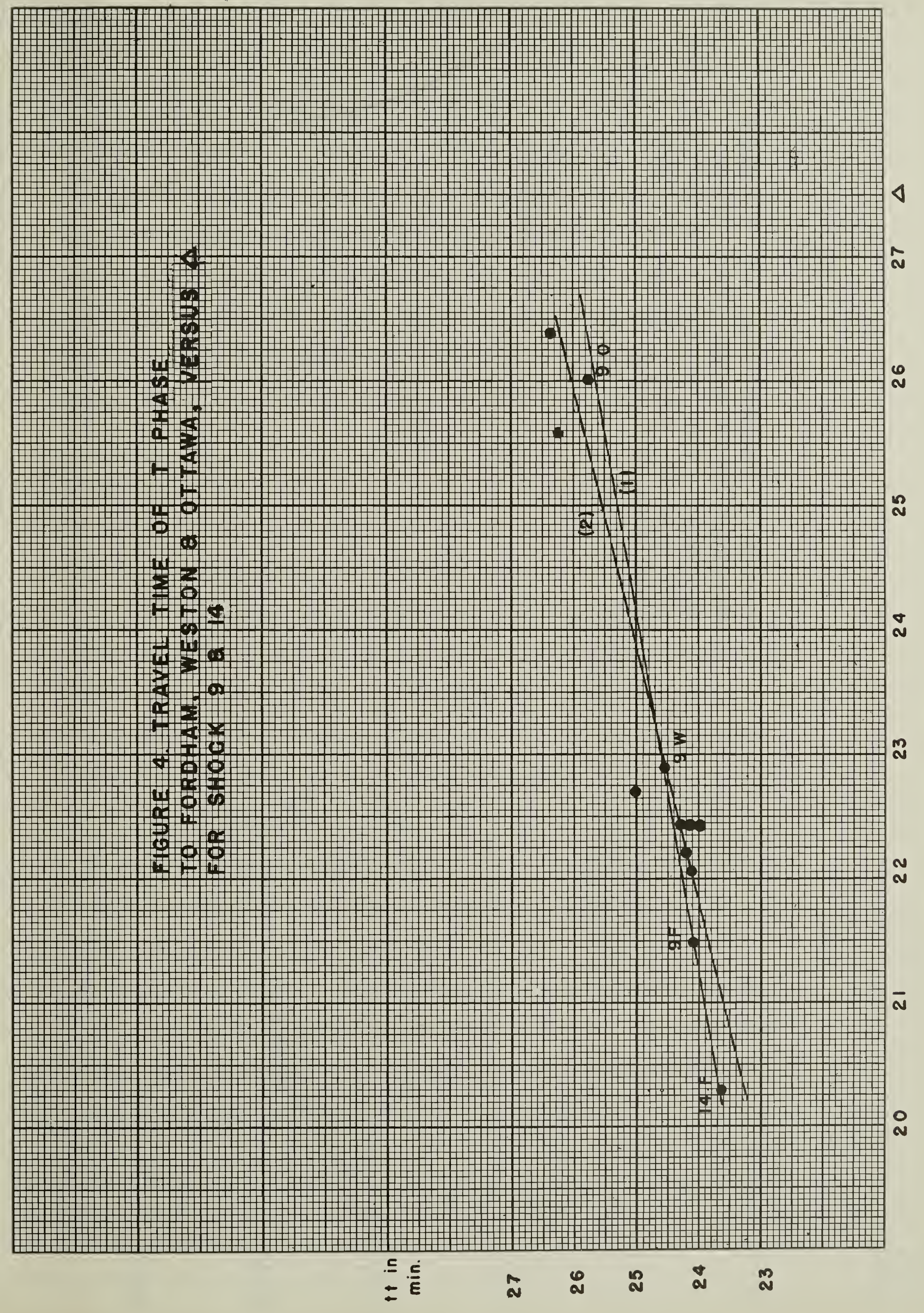




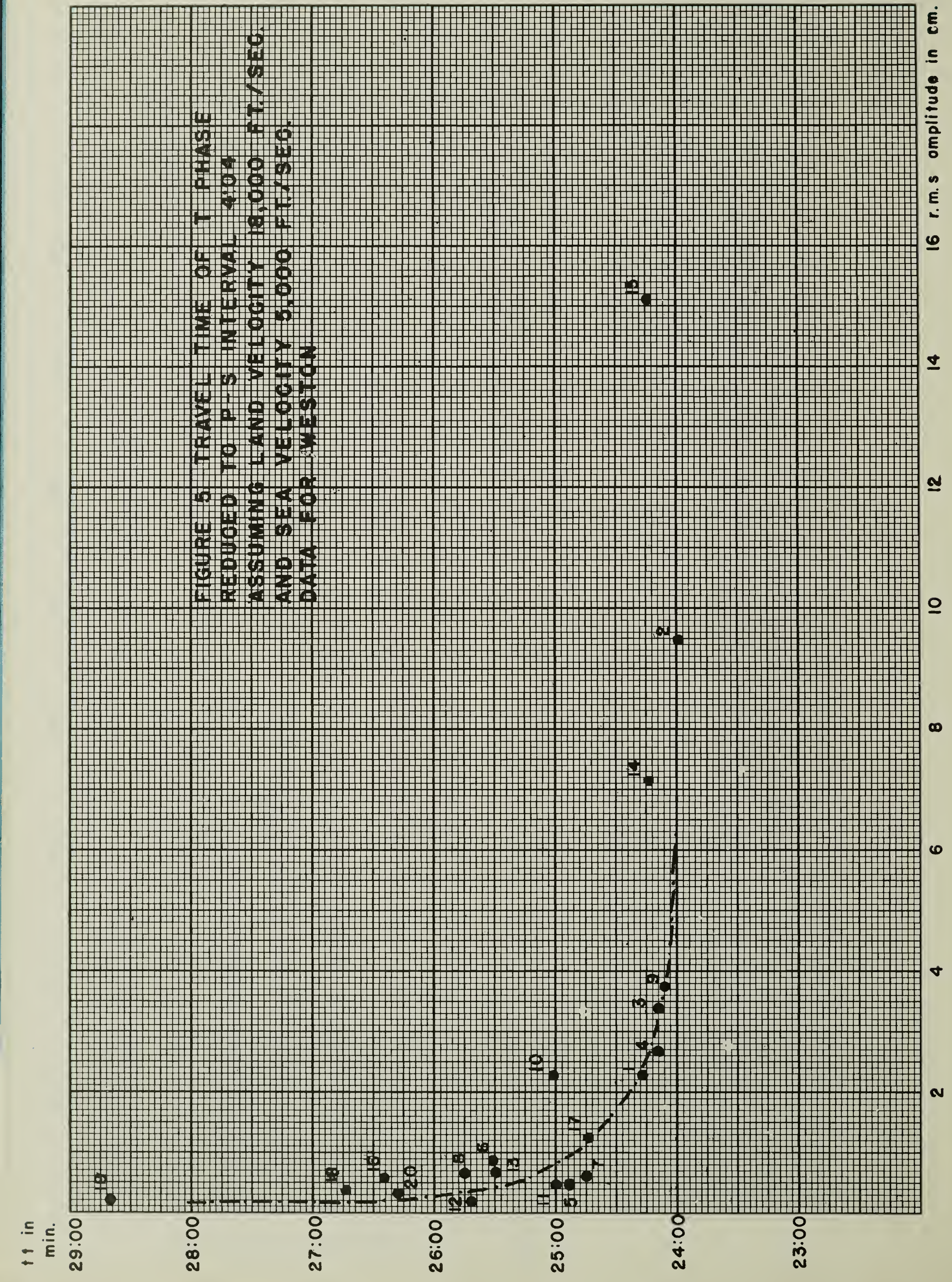


transverse still holds, the picture is much more complex than previously supposed. It is possible to split up the "T" phase into a series of individualized groups of waves, or phases, recognizable on all three components. The criterion for distinguishing a group as such was the occurrence of a sharp break immediately before 1t. A great number of these breaks occur at the same time on all three components. For the four shocks mentioned above we picked all recognizable breaks and measured the maximum double trace amplitudes for each group on all three components. Obviously this could not be done for the very first groups of the "T" phase since the amplitudes are much too small to permit one to obtain any reliable figures.

This procedure was applied to the "T" phases of shocks 3, 4, 14 and 17 as soon as the "T" phase amplitude for at least one component exceeded $0.3 \mathrm{~cm}$. Though it was found impossible to define any definite correlations, several striking similarities for all four of these "T" phases were discovered.

(1) The majority of the various groups making up the "T" phase were characterized by a good sized transverse component. In other words, the amplitudes for the three components were usually such that either $z>E W>N S$ or $E W>z>N S$ and $z=$ EW $>$ NS. Groups shoring this high degree of transverse motion were mostly concentrated in the center of the "TI" phase. The conspicuous groups that correspond to the maximum "T" phase amplitudes (Figure 1) are mostly due to this type of motion. 
(2) There is a large number of groups for which the motion is less transverse. The amplitudes of the three components of these are such that: $z>\mathbb{E W}=\mathbb{N S}$ and $z>N S>E W$ or $z=N S>E W$. These appear to be mostly concentrated at the two extremities of the "T" phase. There are a few such groups interspersed in the central parts of the "T" phase, and may even give (shock 4) the maximum kick of the whole "T" phase. At least one such group always belongs to the center part of the "T" phase, giving one of the series of largest kicks. However, the majority of the se groups is definitely concentrated near the beginning and end of the "T" phase. In particular, the tail of the "TH" phase seems to be mostly constituted of ground movements such that $z=N S>E W$.

It is therefore possible to form the following picture of the readable parts of the "TH" phase: A minute or so after the onset, the ground motion appears to be made up of groups of oscillations some of which are mostly vertical-longitudinal, others being predominantly vertical-transverse. The central part, where the maximum amplitudes occur is mostly characterized by movements of the vertical-transverse type, the transverse component being usually smaller than the vertical one; with these one notes one or two large kicks corresponding to vertical-longitudinal and vertical-longitudinal-transverse $(\mathbb{W}=\mathrm{NS})$ motions. The tail is characterized by predominantly vertical-longitudinal motion, coupled attimes with an appreciable transverse component.

The picture is therefore one of a complex type of motion, which suggests an interpretation in terms of a series of successive 
$P$ and SV-SH arrivals. It is our belief that this would be the kind of picture that one would observe if a short period compressional wave traveling through the ocean would hit the shelf and set up elastic waves at a series of points along the slope. These elastic waves would be both of the $P$ and $S$ types, and would travel through the basement and also through the various sediments of the shelf with the corresponding velocities. Since these waves have very short periods ( $\frac{1}{2}$ sec. and less), and since the thickness of sediments on the shelf is very great, it is quite conceivable that much of the energy of the water wave will be propagated with the velocities of $P$ and $S$ through these sediments. We will examine this question in greater detail when discussing the probable mechanism of transmission of the compressional wave through the water.

As for the importance of the transverse component in the central part of the "T" phase, this can most probably be explained by the transformation from compressional water-waves to elastic waves in a solid at an irregular, inclined interface (the slope of the continental shelf). It is well known that for $P$ waves incident on the boundary of two elastic media there are certain angles for which the transmitted wave becomes predominantly a shear wave. This also occurs in the case where one of the media is a liquid. Also, let us not forget that the recording apparatus is situated in a horizontal plane. In other words, a wave that would be SV with respect to a vertical liquid-solid interface could have an appreclable $\mathrm{F}$ component with respect to a horizontal plane, and 
would produce a transverse component on the seismograms.

\section{The Pacific Darthquakes}

The seismograms at Fasadena, Berkeley, and auxilary stations for all major (magn. larger than 7) Pacific belt shocks of the last ten years were searched, together with a number of recordings of the largest shocks of the preceeding years and of shocks known to have originated off the coast of California and Mexico for the presence of late short period arrivals ("TH phases). These were identified only for five shocks, all of them of magnitude at least equal to 8 . These were:

The March 2, 1933, Japanese shock: Ep. $39^{\circ} \mathrm{N} 144.5^{\circ} \mathrm{E}$,

$$
\mathrm{H}=17: 31: 00 \text { Magn. } 8 \frac{7}{4}
$$

The November 10, 1933, Alaskan shock: Ep. $55.5^{\circ} \mathrm{N} 158^{\circ} \mathrm{W}$,

$$
H=20: 18: 42 \text { Magn. } 8 \frac{1}{4}
$$

The December 7, 1944, Japanese shock: Ep. $33^{\circ} \mathrm{N} 136^{\circ} \mathrm{E}$,

$$
\text { H }=04: 35: 42 \text { Magn. } 8
$$

The December 20, 1946, Japanese shock: Ep. $32.5^{\circ} \mathrm{N} 134.5^{\circ} \mathrm{E}$,

$$
\text { H }=19: 19: 05 \text { Magn. } 8.2
$$

The May 14, 1948, Alaskan shock: Ep. 54. $5^{\circ} \mathrm{N} 161^{\circ} \mathrm{W}$,

$$
\mathrm{H}=22: 31: 42 \text { Magn. } 8
$$

The "Tn phases were also identified on the seismograms of the recently installed short period Benioff seismometers of the Mineral and Mt. Hamilton stations.

Due to differences in noise level and magnification, not all California stations equipped with short period Benioffs record 
these phases. Thus the La Jolla, Santa Barbara and Pasadena stations did not record a single one. Neither did Berkeley, in spite of its more favorable location for the recording of Alaskan "T" phases. However, the Honolulu Neumann Labarre, in spite of its relatively less favorable constants recorded a very pronounced "T" phase for the 1948 Alaskan shock.

The March 2, 1933, shock.

A "T" phase was recorded at Tinemaha. Here $\Delta=72^{\circ} 27^{\prime}$ and $1 \mathrm{~T}=18: 59: 51$, which gives a travel time t.t $=1 \mathrm{hr} .28 \mathrm{~min}$. 51 sec. and a velocity of 4960 feet per sec.

November 10,1938

The "T" phase was recorded for this shock at Tinemaha and Riverside.

$\begin{array}{lcc}\Delta & \frac{\text { Tinemaha }}{30^{\circ} 24^{\prime}} & \frac{\text { Riverside }}{35^{\circ} 161} \\ 1 \text { it } & 20: 54: 07 & 20: 54: 31 \\ t . t & 35: 25 & 35: 49 \\ \text { velocity } & 5560 \% / \mathrm{sec} & 5980 \% \mathrm{sec}\end{array}$

December 7,1944

The "T" phase was recorded at Tinemaha, Mount Wilson, Haiwee, Riverside and Palomaz. 
Minemaha Mt. Wilson Haiwee Riverside Mt. Palomaz

$\begin{array}{lccccc}\Delta & 81032^{\prime} & 83^{\circ} 19^{\prime} & 82^{\circ} 181 & 83^{\circ} 561 & 84^{\circ} 40^{\prime} \\ \text { iT } & 06: 14: 45 & 06: 14: 50 & 06: 14: 43 & 06: 14: 54 & 06: 14: 54 \\ \text { t.t } & 1: 39: 03 & 1: 39: 08 & 1: 39: 01 & 1: 39: 12 & 1: 39: 12 \\ \text { velocity } & 50051 / \mathrm{sec} & 50201 / \mathrm{sec} & 5070^{\prime} / \mathrm{sec} & 5155^{1} / \mathrm{sec} & 5190 \% \mathrm{sec}\end{array}$

December 20, 1946

The "T" phase was recorded at Riverside. It was first tentatively identified at Mt. Wilson and Palomar, but these had to be discarded owing to their similarity to similar minor disturbances on the record. They did not have the aspect characteristic of this phase for records of stations (even shorter duration and smaller amplitudes, and besides their times were too much at variance with each other). They were mach more suggestive of minor disturbances of extraneous origin.

\begin{tabular}{|c|c|c|}
\hline \multirow[t]{4}{*}{ At Riverside: } & $\Delta$ & $85^{\circ} 14^{\prime}$ \\
\hline & $1 T$ & $21: 02: 16$ \\
\hline & t.t & $1: 43: 11$ \\
\hline & velocity & $50201 / \mathrm{sec}$ \\
\hline
\end{tabular}

May 14, 1948

The "T" phase was identified here for the Tinemaha, Riverside, Mineral, Mt. Hamilton and Honolulu stations.

$\begin{array}{lccccc} & \text { Mineral } & \text { Mt. Hamilton } & \text { Honolulu } & \text { Tinemaha } & \text { Riveriside } \\ \Delta & 29040^{\prime} & 31^{\circ} 42^{\prime} & 33^{\circ} 16^{\prime} & 33^{\circ} 47^{\prime} & 36^{\circ} 31^{\prime} \\ 11 & 23: 09: 07 & 23: 10: 31 & 23: 12: 38 & 23: 09: 37 & 23: 11: 15 \\ \text { t.t } & 37: 25 & 38: 49 & 40: 56 & 37: 55 & 39: 33 \\ \text { velocity } & 4820 \% \mathrm{sec} & 4965 \% \mathrm{sec} & 5000 \% / \mathrm{sec} & 5410 \% / \mathrm{sec} & 5690 \% \mathrm{sec}\end{array}$


None of the "T" phases were recorded at Tucson. This sets an upper limit for their penetration inland, of the order of 500 miles for these shocks.

Now let us examine these travel times and velocities in the light of what we know of the behaviour of the "T" phase of the Dominican Republic shocks as recorded at Weston and Ottawa. We observe that for the two Alaskan shocks the "T" phase velocities for the same stations are higher than for the Japanese shocks. The reason for this may be seen immediately by drawing the great circle paths to the epicenters of the corresponding shocks: a large portion of this path for the Alaskan shocks is continental, as against a much smaller portion for the Japanese shocks. For a given shock, (December 1944, May 1948, November 1938), the greater the distance of the station inland with respect to the epicenter, the higher is the velocity obtained. This phenomenon is really the same as the preceeding. It is completely in accord with our hypothesis. The velocities obtained at Riverside for the two Alaskan shocks are of the order of 6000 and 5700 feet per sec. The length of the continental path being of the order of $5.5^{\circ}$ to $6^{\circ}$, a rough computation reveals that if this section of path corresponds to a velocity of the order of that of $P$, then the velocity for the oceanic path must be of the order of magnitude of that of sound in water. Rough computations of this kind will give similar results for all but two stations (Mineral and Mt. Hamilton), and for all shocks.

Finally the velocity of 5000 feet per sec. as given by 
the Honolula record for the May, 1948, shock is a highly significant result, since the path was here entirely oceanic. Within the limits of error of epicenter determination, 5000 feet per sec. is the velocity of sound in water.

There are a few obvious but relatively minor discrepancies, such as the small velocities obtained at Mineral and Mt. Hamilton, and the slightly lower velocity of the March 3, 1933, shock at Tinemaha ( $\Delta=72^{\circ} 27^{\prime}$ ) as compared to the velocity obtained at the same station for the December, 1944, shock $\left(\Delta=81^{\circ} 33^{\prime}\right)$. whereas it is the reverse that one would have expected to find. However, these are not serious objections. At Weston, for epicentral distances of only $22^{\circ}$, and with a very favorable azimuth (the water wave came in at practically normal incidence to the shelf), wo could use only the lerger shocks in order to obtain reliable figures for iT. It is only natural that we should have run into greater troubles for the case of the California stations and Pacific shocks where some of the paths are considerably greater (Japanese shocks), the continental paths are much longer (in particular for the Alaskan shocks), and worst of all, the water wrave comes in at large angles of incidence. The amplitudes of the "T" phase are consequently very small $(0.1 \mathrm{~cm}$ and less). The total duration of the signal is extremely variable and gives us no indications as to the reliability of the iT times read. We can only hazard rather rough guesses as to the true lengths of the paths followed. It is therefore not surprising that we get occasional discrepancies (as we did at Fordham). 
It is important to note that the above data obtained from the California records for Japanese and Alaskan shocks do not fit any of the classical earthquake phases. For the Japanese shocks the travel times are much larger than those for any combinations of core reflections and refractions. For the Alaskan shocks the epicentral distance is too small for the appearance of PKKP, SKKS and derived phases. Besides the differences in travel time for some of the stations suggest strongiy that our phase is propagated over the continental portions of its path with a velocity approximating that of standard $P$ and $S$ waves.

The "T" phases observed are not aftershocks of the main quakes since these would not give such variable arrival times, and the arrival times would only be functions of the distance and not of azimath. Besides they do not show up on the seismograms of instruments having constants different from those of the Benloff short period. The same reasoning applies to their possible interpretation as locel shocks. The time differences between successive pairs of stations are such that it is impossible to find a corres ponding epicenter lacation. (December, 1944, and May 1948, shocks)

The presence on the records of this late short period arrival, which within the limits of allowable error fits the predictions of the theory, and cannot be made to fit any other interpretation, can hardly be regarded as coincidental, since it is to be found in association with five large Pacific shocks.

Figure $6 a$ and $b$ shows the "T" phases as recorded on the Benioff short period verticals of Tinemaha and Riverside respectively, 
for the Norember 10,1938, Alaskan shock ( $H=20: 18: 42)$. The amplitudes are seen to be relatively much smaller than those recorded at Weston for Dominican Republic shocks.

\section{Mechanism of Transmission of the Short}

\section{Period Water Wave over Great Distances}

It has been shown by Hwing and Worzel ${ }^{8}$ that under certain conditions, sound from a small bomb exploded at sea can be picked up by hydrophones at very great distances, signals from a small bomb having been heard as far as 3100 miles. Bathythermograph investigations in the Atlantic Ocean hove shown that there exists a minimum velocity layer, the axis of which is situated at a depth of 700 fathoms. The velocity gradient in both directions away from this minimum velocity axis is approximately linear. If a source of sound is placed in the vicinity of the axis, all the rays included within a certain solid angle will never reach either the bottom or the surface of the ocean, but will be forever refracted up and down across the axis; their paths will consist of a succession of circular arcs, successively convex (when above the axis) and concave towards the surface (when below the axis). This low velocity layer forms therefore a sound channel, by means of which sound rays can be propagated over thousands of miles with little attenuation. The sound channel has been named the SOFAR channel, after its practical application (sound fixing and ranging).

8. Ewing and Worzel, loc. cit. 

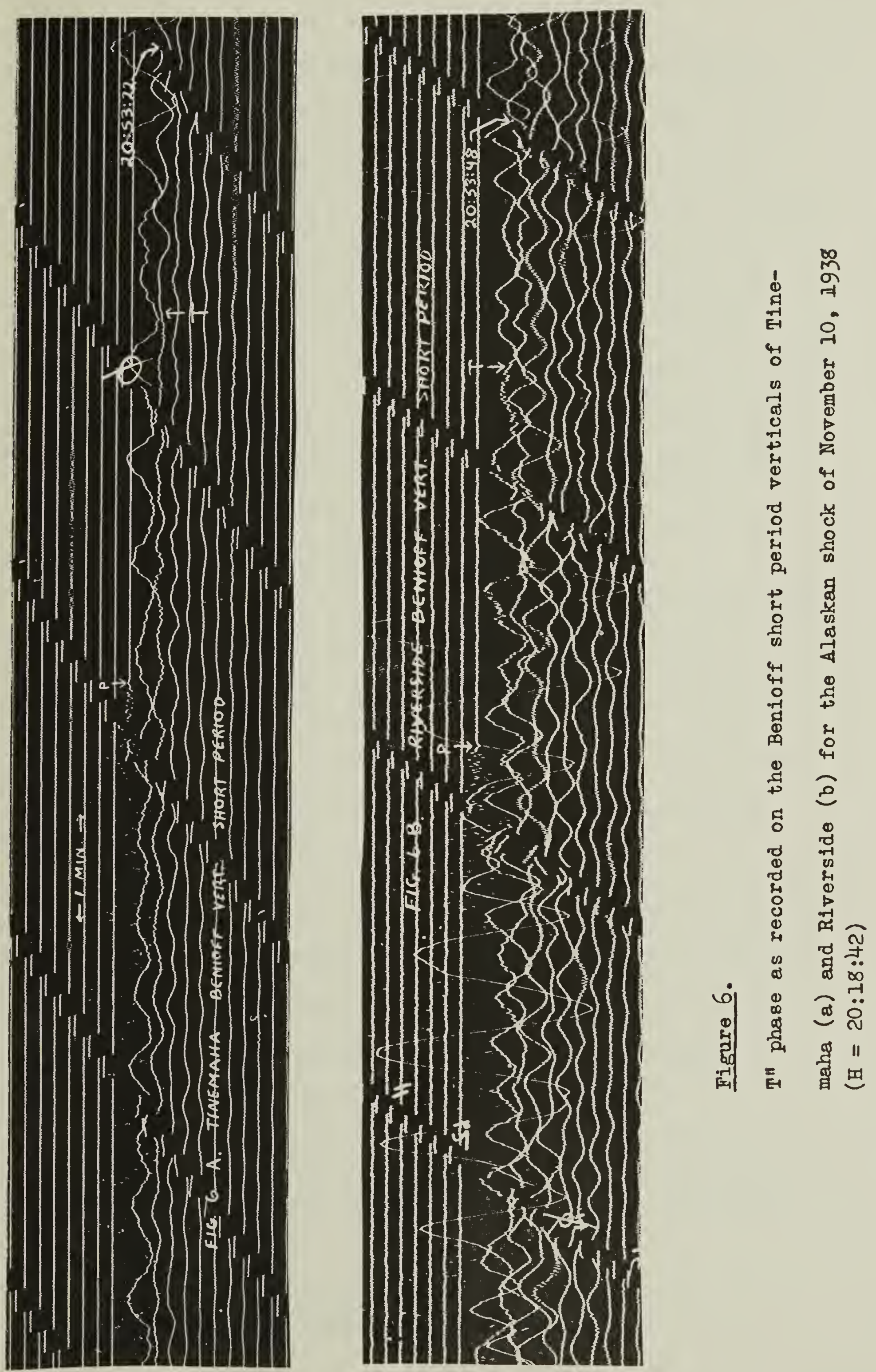

It can be seen intuitively, and it has been verified experimentally, that all other rays produced by the sound source (the angle of emission of which is too large to allow them to remain within the channel) will be attenuated more readily, since they will be propagated through the water by successive total reflections off the bottom and surface. As long as the wave length of the sound produced is small compared to the width of the channel, it will be able to propagate through it over great distances. Therefore, the total width being of the order of 18000 feet, it is seen that sound of period less than 1 sec. can be propagated by this mechanism.

The short period phase predicted by the normal mode theories of Pekeris ${ }^{9}$ and Press and Fwing ${ }^{10}$ assume a constancy of velocity with depth in the ocean and can also account for a "T" phase with periods of 1 second or less. Since normal mode propagation consists - essentially of constructive interference between multiply reflected rays, attenuation effects due to irregularities in the ocean bottom are more likely to occur than in sofar propagation. It appears probable therefore that, although the "T" phase of the various shocks we have studied can be propagated by either means, propagation through the sound channel accounts for the major part of the observed "T" phase.

We see immediately that it will only be under favorable conditions that "T" phases will be found for distant sea quakes.

9. C. L. Pekeris, loc. cit.

10. Frank Press and Maurice Ewing, loc. cit. 
The primary condition for sound to travel in the channel is that the source be situated within the channel. No matter how large the area of the source, and no matter how great the energy produced by it, if it is situated entirely outside of the channel, the compressional sound waves it produces will fail to record at great distances, since they will lose most of their energy through successive total reflections off the bottom. Therefore, if an earthquake occurs at sea on a flat ocean bottom at a depth of more than 2700 fathoms, it is questionable whether it will produce a "T" phase. If, however, the epicenter of the shock is situated on the slope of a deep, such as the ones that are to be found north of the Dominican Republic, east of Japan and south of the Alaskan peninsula, we will have optimum conditions for the transmission of a "T" phase. We see, therefore, the significance of the geographical distribution of the shocks that have produced recognizable "TI" phases.

The manner of transmission of the "TI" phase throws some light on the main features of the Weston recordings. Theory predicts, and experiment confirms, that for a point source in the axis the greatest energy is carried by those rays that deviate the least from the axis of the channel. However, individual rays may, at their apex, reach the outer limits of the channel. In other words, they may graze the surface and also the 2700 fathom level. The amount of energy carried by these outer rays will certainly be appreciable in the case where the source is finite (earthquakes). Therefore, upon reaching the very outer edge of the shelf, at deptlms slightly less than 2700 fathoms the transfer of energy into elastic 
wares will begin. This transfer will occur continuously all along the slope of the shelf. The amount of energy transferred will be maximum at the points of the slope situated at the same depth as the axis of tho SOFAR channel, i.e., 700 fathoms for the Atlantic. This will correspond to the maximum amplitudes of the derived elastic waves. This feature will be further accentuated by the fact that it is between 1500 and 100 fathoms that the continental slope is steepest. From our present knowledge of the structure of the continental shelf! the largest impulse would therefore be given to the sedimentary layers of the shelf.

Thus it appears possible to provide a qualitative explanation, in the light of this mechanism, of the main features of the "T" phase on the Weston records. The very slow build-up would be due to the fact that the first arrivals will have originated at the foot of the continental slope, fromthe relatively smaller sound impulses travelling along the outer edge of the channel.

In the case of the smaller shocks, the energy of these first impulses would be too small to produce elastic wares of sufficient amplitude to be visible above the noise level. This would explain the large variations in apparent travel time. In the case of very large shocks one might even expect a series of more or less continuous smaller tremors preceding the main body of the "T" phase, since great areas of the ocean floor preceeding

11. Maurice Ewing, A. P. Crary, and H. M. Rutherford, Geophysical Investigation in the Emerged and Submerged Atlantic Coastal Plain, Part I, Geol. Soc. Amer., Bull., Vol. 48, pp 753-802, 1937 
the foot of the shelf are shoaler than 2700 fathoms. This feature is indeed observed.

Let us know consider the negative evidence, and see if our theory is capable of accounting for the absence of a "T" phase for some of the major sea quakes in recent years. The only Atlantic sea quakes that have produced "T" phases are those that have occurred north of the Dominican Republic. None of the Mid-AtlanIic Ridge shocks have given any on the Weston and Fordham records.

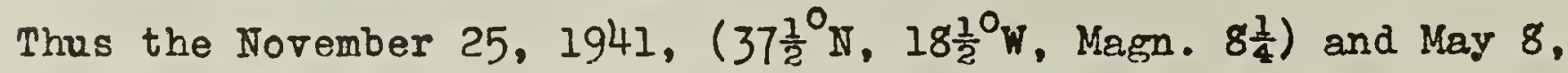
1939. ( $37^{\circ} \mathrm{N}, 24^{\circ} \mathrm{W}$, Magn. order of 7 ) Azores shocks show no "T" phase. Neither did the April 11, 1946, (12.80 W, 4. $0^{\circ} \mathrm{S}$, Magn. $7 \frac{1}{4}$ ) and a series of other smaller Mid-Atlantic shocks give anything. The two Azores shocks and the April 11, 1946, shock occurred on the far side of the Mid-Atlantic Ridge. Since the latter forms a continuous high barrier across the Atlantic, it should efther stop entirely the sound that is being propagated through the channel or at least interfere with its transmission effectively enough to reduce the amount of energy carried to a small fraction of its initial value. For the Azores shocks the interference would be complete, since both the Azores Plateau and the Ridge west of the Azores are very high in these latitudes. For the April 11, 1946, shock, the absence of a "m" phase would be due to a high degree of interference (probably not complete) combined with the effect of distance.

All other Mid-Atlantic Ridge shocks, from 1939 through 1947, including May 6, 1944, occurred in scattered spots along the 
Mid-Atlantic Ridge. They were all of class $c$ or less, and have rather uncertain epicenter locations. Generally speaking, they are distributed through the High Centrel zone of the Ridge. Due to the type of ocean bottom topography that is known to prevail there, the probability of their having occurred under the best conditions for the transmission of a "T" phase is exceedingly small. One should also keep in mind that even if a "T" phase were produced, it would be small since the shocks are small. It would have to propagate over greater distances than the Weston-Dominican Republic epicentral distances. It would have a large angle of incidence relative to the continental shelf. From the above data we see that the chances of its recording would be very small indeed.

As for the Pacific shocks, only shocks whose epicenters are situated along the sides of the Japanese and Aleutian deep sea troughs, and the magnitude of which was at least 8 have produced "T" phases recorded on land. It appears, therefore, that the recording of a recognizable "T" phase depends to a large extent on the magnitude of the shock, since all shocks of magnitudes between 7 and 8 for the last seven or eight years rere investigated. This dependance on magnitude is probably due to the unfavorable azimuths of arrival combined with large epicentral distances. It is probable that hydrophones placed at a suitable depth would record "m" phases travelling through the SOFAR channel for a mach greater number of shocks (both Atlantic and Pacific). The "T" phases would record on seismometers situated on land only under particularly favorable conditions, which mav occur only as a combination of 
several factors such: optimum conditions at epicenter for production and transmission of sound in water, favorable azimuth of epicenter with respect to station, large magnitude of shock, absence of barriers interferring with SOFAR transmission. Since the sound channel is absent in Polar regions, "T" phases of shocks with epicenters in these regions may be very small or entirely absent.

\section{Practical Applications}

Before concluding this report, we would like to mention two possible practical applications of the "Tn phase. Owing to its low velocity, the "T" phase could be used as an additional and perhaps powerful method for obtaining accurate epicenter locations. Standard SOFAR equipment would be best suited since, as we have seen, the arrival times on land are subject to too many sources of errors, for which it is impossible to provide accurate corrections.

The second practical possibility resides in a feature of the "Ti" phase producing shocks which has not yet been mentioned. Of the five Pacific shocks that produced "T" phases on land, four (March 2, 1933; November 10, 1938; December 7, 1944; December 20, 1946) had produced tsunamis. During the entire period covered by the study, only five tsunamis occurred in the Pacific for which "T" phases could have been recorded because of the absence of barriers, so that only one tsunami was not accompanied by an observable "T" phase since 1933. The August 4, 1946, Dominican

12. N. H. Heck, List of Seismic Sea Wares, Bull. Seism. Soc. Amer., Vol. 37. No. 4, pp 269-286, 1947 
Republic shock produced a destructive tsunami. The August 8 shock may also have produced a small one (St. Georges, Bermada, tital gage record).

It appears, therefore, that "T" phases are produced either in association with tsunamis, or at least, in locations in which the latter have been known to originate. It seems as if there might be a definite similarity between the type of mechanism that produces many tsunamis and that which produces "T" phases. It is well known that the size of a tsunami is not a direct function of magnitude of the shock only. There are other factors which enter into its production. The exact nature of these is still an object of speculation. One however, appears to be the location of the epicenter. Thus all tsunami producing shocks were located on, or in the immediate vicinity of a slope.

Though some tsunamis have been interpreted as originating from submarine landsildes, 13 it is by no means certain that this is their general cause. It is possible that landslides originate as a result of the same mechanism that produces the tsunami, and that they are thus another effect of this mechanism, and not its primary cause.

Tectonic movements, such as displacement along a fault close to the surface of a submarine slope, can be visualized as having sufficient impact to produce the long tsunami waves. This should undoubtedly set up short period sound waves or "T" phases which would be propagated through the SOFAR channel.

13. Beno Gutenberg, Tsunamis and Earthquakes, Bull. Selsm. Soc. Amer., Vol. 29, No. 4, pp 517-526, 1939 
The degree of correlation of "T" phases with tsunami producing shocks is startling, and may well not be fortuitous. It is entirely conceivable that the extremely high ratios of the "T" phase amplitudes to the "P" and "S" amplitudes as recorded at Weston for the August 4, 1946, Dominican Republic shock (which produced a destructive tsunami) is a general feature of all tsunami producing shocks.

It is to be noted that the April 1, 1946, shock, which produced an extremely destructive tidal wave in Hawail, did not produce a "T" phase recorded on land. However, it has been seen that no Pacific shock of magnitude less than 8 has shown "ị" phases, due to unfavorable conditions for their recording. It may well be that a hydrophone in the SOFAR Channel would have shown a high amplitude short period phase coming in, even though at that period of the year the SOFAR Channel would be practically absent above $50^{\circ} \mathrm{N}$

It is entirely conceivable, therefore, that if a suitable series of records could be obtained, an adequate calibration of the amplitudes of the short period sound waves travelling in the SOFAR Channel versus the magnitude of the shock could be of great use in the forecasting of tsunamis, since the velocity of the latter is 8 to 9 times less than that of the "T" phase. 


\section{Acknowledgments}

The authors wish to express their thanks to

Professors B. Gutenberg and C. F. Richter of the California

Institute of Technology for their help and cooperation in making a large number of Pasadena records available. We are also greatly indebted to Father Daniel Linehan, S. J., of the Weston Seismological Observatory, whose records went far towards making this investigation possible. Dr. T. A. Hodgson of the Dominion Observatory of Canada in Ottawa, Professor Perry Byerly of the University of California, Father John J. Lynch, S. J., and Dr. William A. Lynch of Fordham University, and the Officers of the U. S. Coast and Geodetic Survey, Sections of Seismology and of Tides and Currents, were extremely helpful during this investigation. 


